\title{
Associated malformations in the family of a patient with Meckel syndrome: heterozygous expression?
}

\author{
Reena Gulati, Shubha R Phadke, S S Agarwal
}

\section{Department of Medical Genetics, Sanjay Gandhi Post Graduate Institute of Medical Sciences, Raebareli Road, Lucknow 226014, India R Gulati \\ $S$ R Phadke \\ S S Agarwal}

Correspondence to: Dr Phadke.

Received 23 January 1997 Revised version accepted for publication 14 May 1997

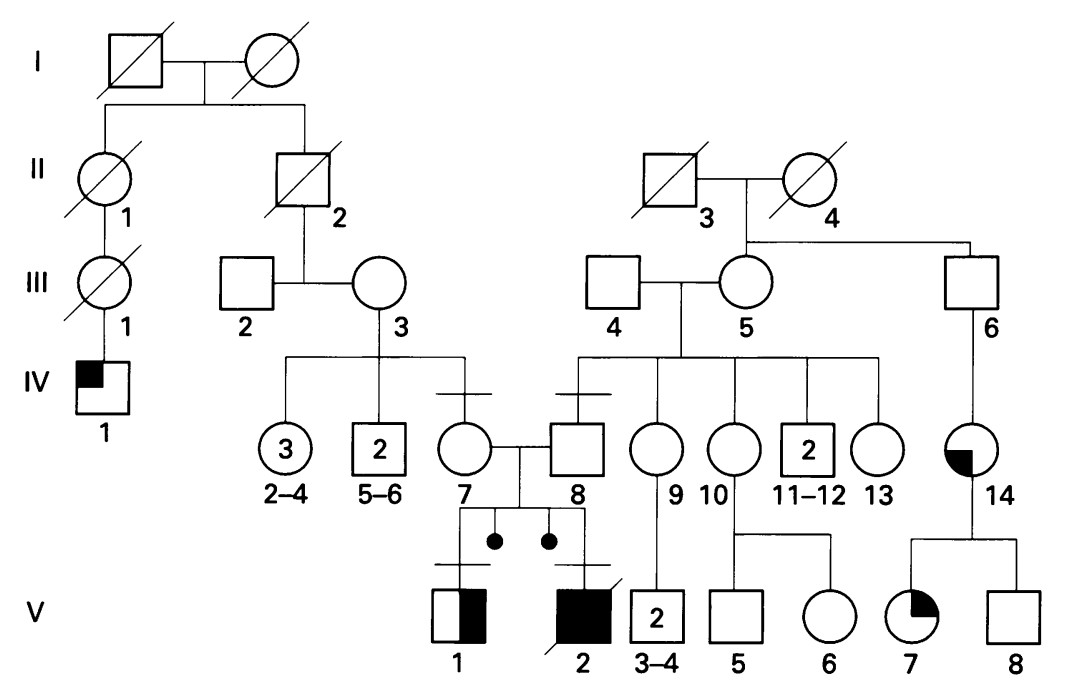

\begin{abstract}
Meckel syndrome is an inherited autosomal recessive disease. A family is described in which four persons had minor malformations related to the syndrome, suggesting the possibility of manifesting heterozygotes. It is uncertain whether these malformations represent partial expression of the disease or are coincidental. However, partial expression has been described in heterozygotes for other autosomal recessive diseases. Until the gene responsible for this lethal syndrome is cloned and sequenced, such relatives of the proband may be offered genetic counselling and prenatal diagnosis.

(f Med Genet 1997;34:937-938)
\end{abstract}

Keywords: Meckel syndrome; manifesting heterozygotes; genetic counselling

Autosomal recessive diseases may occasionally be expressed in heterozygotes by mild manifes-

tations or at a biochemical level, as in the haemoglobinopathies and some metabolic disorders. However, the vast majority of autosomal recessive heterozygotes are asymptomatic. This is particularly true where the homozygote presents with multiple congenital anomalies.

We present a case of Meckel syndrome, an autosomal recessive condition characterised by occipital encephalocele, cystic dysplasia of the kidneys, and polydactyly. In the family, four possible heterozygotes showed minor manifestations of the syndrome.

\section{Case report}

A couple was referred for genetic counselling at 24 weeks of gestation because ultrasound had shown an occipital encephalocele and polycystic kidneys in the fetus. The mother and father were aged 23 and 27 years respectively and denied consanguinity. Their only child, a son aged $31 / 2$ years (fig $1, V .2$ ), had a repaired bilateral cleft lip and palate. He had no other congenital anomaly. His physical growth and developmental milestones were appropriate for his age.

A paternal first cousin (fig 1, IV.14) was reported to have preaxial polydactyly, and her daughter (fig 1,V.7) had a cleft lip. The mother was aware of a second cousin (fig 1, IV.1) who had total syndactyly of all five toes of the left foot.

The pregnancy was terminated. The fetus had a broad and depressed nasal bridge, telecanthus, macrostomia, micrognathia, malformed, low set ears, and a small neck. There was a ruptured occipital encephalocele. A large dimple in the scalp above the base of skull showed a circular defect in the underlying occipital bone. There was postaxial polydactyly of both hands. The toes were normal. The external genitalia were normal male. Both kidneys were enlarged wih a lobular surface. The ureters were hypoplastic. The liver-heart weight ratio was 10:1 (normal 4:1-7:1). All other organs were normal. Histopathological examination of the kidneys showed multiple variably sized cysts. There were no cysts or fibrosis in the liver or pancreas. Necropsy findings were consistent with the diagnosis of Meckel syndrome. It was explained to the parents that there would be a $25 \%$ recurrence risk in future pregnancies.

The parents had no minor manifestations of Meckel syndrome. Ultrasonograhy of the abdomen of the parents and their only son was normal. 


\section{Discussion}

Fetal postmortem examination confirmed the diagnosis of Meckel syndrome. This disorder may be overlooked in a fetus/neonate with a neural tube defect if other anomalies are not carefully looked for. In such a case, the recurrence risk will be given as that for a multifactorial disorder rather than for an autosomal recessive condition.

In our case, cleft lip and palate, one of the major diagnostic criteria for Meckel syndrome, ${ }^{1}$ was absent, but was present in the sib. This suggested the possibility that he was a heterozygote with partial expression of this autosomal recessive condition. Cleft lip, polydactyly, and syndactyly, part of the clinical spectrum of Meckel syndrome, ${ }^{1}$ were reported in some relatives of the family (fig 1). Some authors have described minor or major malformations in relatives of patients with Meckel syndrome. In 1994, Nelson et al reported a family with three affected males in which the father and his first cousin both had postaxial polydactyly of the feet. Salonen ${ }^{3}$ studied the largest series of congenital anomalies in relatives of patients with Meckel syndrome. Twelve of the 42 families reported had anomalies in relatives.

Anencephaly, syndactyly, cleft lip/palate, palatal type of speech impediment, limb anomalies, including short or absent digits/ limbs, bifid kidneys, hypospadias, and congenital heart disease, have been reported in relatives. ${ }^{3-6}$ These malformations are part of the complex of Meckel syndrome ${ }^{1}$ and may repre- sent incomplete expression of the condition in heterozygotes.

It has been suggested that the occurrence of minor malformations in relatives of patients with Meckel syndrome may be the result of heterozygote expression. It will be possible to confirm this hypothesis once the gene for this syndrome has been sequenced and disease causing mutations are identified. The locus for Meckel syndrome is mapped to chromosome 17q21-q24.

In the meantime, the relatives require careful examination for the presence of any related congenital anomaly. Such information may be helpful when providing genetic counselling and prenatal diagnosis. However, Meckel syndrome is an autosomal recessive condition and the risk to the offspring of relatives should be small provided that the marriage is not consanguineous.

1 Johnson VP. Meckel syndrome. In: Buyse ML, ed. Birth defects encyclopedia. Dover, USA: Centre for Birth Defects Information Services Inc, 1990:1113-14.

2 Nelson J Nevin NC Hanna EJ. Polydactyly in a carrier of the gene for the Meckel syndrome. Am $\mathcal{F}$ Med Genet 1994; 53.207-9.

3 Salonen R. The Meckel syndrome: clinicopathological findings in 67 patients. Am $\mathcal{F}$ Med Genet 1984;18:671-89.

4 Hsia YE, Bratu M, Herbordt A. Genetics of the Meckel syndrome (dysencephalia splanchnocystica). Pediatrics 1971; 48:237-47.

5 Marshall R, Newnham RE, Rawstron JR, et al. Features of the 13-15 trisomy syndrome with normal karyotype. Lancet 1964;i:556.

6 Fitch N, Pinsky L. The Meckel syndrome with limited expression in relatives Clin Genet 1973;4:33-7.

7 Paavola P, Salonen R, Weissenbach J, Peltonen L. The locus for Meckel syndrome with multiple congenital anomalies maps to chromosome 17q21-q24. Nat Genet 1995;11:21315 . 